\title{
Facing Service-Oriented System Engineering Challenges: An Organizational Perspective
}

\author{
Zheng Li \\ NICTA and UNSW \\ School of CSE \\ Sydney, Australia \\ Zheng.Li@nicta.com.au
}

\author{
He Zhang \\ NICTA and UNSW \\ School of CSE \\ Sydney, Australia \\ He.Zhang@nicta.com.au
}

\author{
Liam O’Brien \\ NICTA and ANU \\ Research School of ISE \\ Canberra, Australia \\ Liam.OBrien@nicta.com.au
}

\begin{abstract}
Over the past decade, Service-Oriented System Engineering (SOSE) has emerged as one of the most important research areas to help industry achieve many goals such as agility, flexibility, reusability and efficiency. However, SOSE is still suffering from numerous and a broad scope of challenges. Although challenges usually imply research opportunities in academia, too many challenges will inevitably constrain the applicability of corresponding research topic to industry, and in turn spoil the vitality and development of the relevant research area. Therefore, it is necessary to find efficient approaches to facilitate decreasing current challenges and relieving the research effort in the area of SOSE. Through treating SOA system as an instance of organization, this paper justifies that we can introduce existing work in organization theory area to current challenges of SOSE. As a demonstration, four preliminary solutions that have been successfully applied to organizational area are identified to meet four challenges scattered under four research topics of SOSE.
\end{abstract}

Keywords- Service-Oriented System Engineering (SOSE); Service-Oriented Architecture (SOA); organization theory; organization design; challenges

\section{INTRODUCTION}

Service-Oriented System Engineering (SOSE) emerges with the requirements of quick response to the rapid and often unpredictable changes in business environment for modern enterprises. However, numerous challenges have appeared along with the development of SOSE [4, 7, 14, 15, 17, 18]. Although $\mathrm{Gu}$ and Lago [7] claim that the number of SOSE challenges has decreased and become stable, existing challenges still cover a wide range of SOSE area. Considering that a large scope of challenges of a research topic will inevitably constrain the topic's influence on industry and in turn spoil the relevant research area, we must find efficient approaches to facilitate decreasing current challenges and relieving the research effort in the SOSE area.

To inspire the research into efficiently achieving solutions to SOSE challenges, we propose to borrow the experience and existing work from other disciplines. Through viewing Service-Oriented Architecture (SOA) from an organizational perspective and treating SOA implementations as organizational activities, this paper switches the research environment of SOSE from the SOA domain to the organization theory domain. The solutions to the challenges of SOSE can then be explored under the umbrella of organization theory. Enlightened by existing work of organization design in the organization theory domain, we have identified four solutions as a demonstration to satisfy several challenges in four predetermined SOSE research topics [14]: (1) to build business process teams to facilitate mapping between business structure and serviceoriented environment in the Business topic, (2) to use Total Quality Management (TQM) to accommodate to the Quality Assurance challenge in the Engineering topic, (3) to keep the structure as flat as possible to meet the Adoption challenge in the Operations topic, and (4) to take measurements at interim steps in process to satisfy the Governance challenge in the Cross-Cutting topic.

Overall, this paper makes three contributions. Firstly, new interdisciplinary research opportunities are brought between service-oriented theory and organization theory. Secondly, new method of investigating solutions to current challenges in SOSE area is outlined. Thirdly, four preliminary solutions enlightened by organization design have been identified.

The remainder of the paper is organized as follows. Next section justifies thinking of SOA from the organizational perspective. Section III introduces four preliminary solutions enlightened by organization design for SOA implementation. Conclusions are drawn and some future work is proposed in section IV.

\section{VIEW OF SOA SYSTEM FROM AN ORGANIZATIONAL PERSPECTIVE}

Organizations emerged as early as ancient civilizations appeared. Today, organizations have become indispensable and pervasive components of human beings' society, for example, from schools to hospitals and from armies to governments. When it comes to the SOA area, we can similarly regard service-oriented systems as organizations that are composed of services. As shown in Figure 1, both traditional organizations and SOA systems consist of organizational units. Organizational units in an SOA system are services, while that in a traditional organization are individuals. Furthermore, different organizational units have different skills and play different roles in an organization. For example, composite services play integrative roles in an SOA system, which parallels the responsibilities of managers in a traditional organization. 


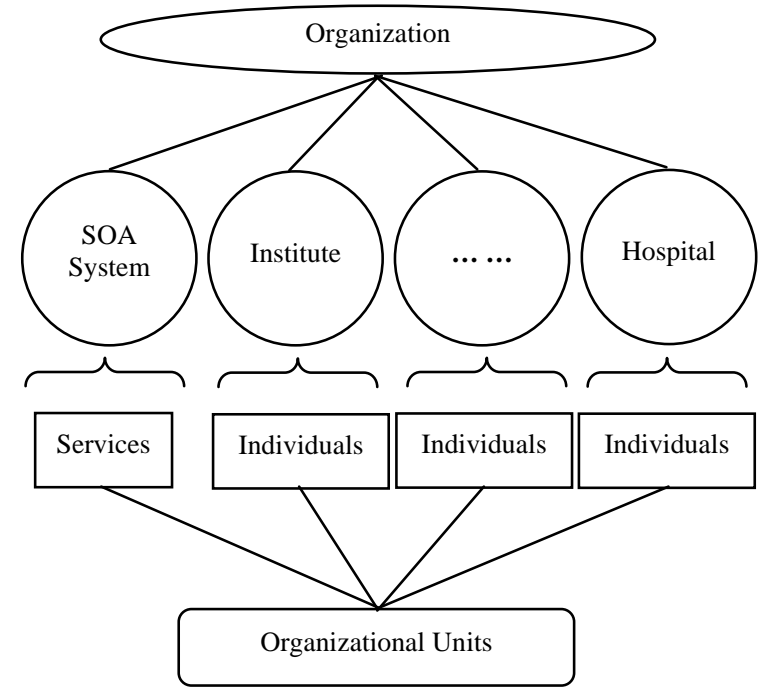

Figure 1. Think of SOA from the Organizational Perspective.

However, there is no single agreed definition of an organization. Fierce debates about the organization concept are still underway, although theorists have traditionally consented that organizations are collectivities of people who are socially arranged to pursue specific purposes and achieve explicit goals [1]. This traditional consensus already makes it possible and proper to think of SOA using the organizational perspective, which is mainly based on two reasons.

On the one hand, it is suitable to think of SOA as a form of organization architecture. The Organization for the Advancement of Structured Information Standards (OASIS) [2] defines SOA as "a paradigm for organizing and utilizing distributed capabilities that may be under the control of different ownership domains. It provides a uniform means to offer, discover, interact with and use capabilities to produce desired effects consistent with measurable preconditions and expectations." When it comes to implementation, SOA is used to build up a collection of independent services that can be quickly and easily integrated into different, high-level business services and business processes to create business value and achieve business strategies [3]. To summarize, SOA both in theory and in practice is proposed for organizing services to attain some particular goals. Therefore, SOA can be set under the umbrella of organization theory following the suggestion of traditional organization concept: if the process of organizing is about goal attainment, the organization theory could be followed to conceptualize, explain and ultimately guide individuals' activities that should be united together to achieve desirable, common organizational goals [1].

On the other hand, it is reassuring to think of SOA from the organizational perspective. In fact, conceptual dangers might occur when talking of organizations based on having a goal, because the agreement about an organization's purpose amongst members may not exist. In SOA area, however, this disagreement issue can be ignored. Within SOA systems, a service is a well-defined unit of functionality realized by a service interface and a service implementation [4]. A service interface identifies a service and exposes the semantic description of the service's invocation. A service implementation realizes the work that the service is designed to perform. Unlike people in social organizations, services in SOA do not have mental or psychological attributes. Consequently, services will always obey the control from "senior manager" of the whole SOA system, and may even not be aware of the "organizational goal". When thinking about SOA organizationally, the blind obedience characteristic of services can naturally avoid the dangers of defining organizations in terms of having a goal while not all members freely agree to that goal [5].

Moreover, SOA system and organization have similar features. Campbell and Craig [6] have identified seven general characteristics about the organizations, as shown in the left column of Table I. We can then list the comparable features of SOA system in the right column.

TABLE I.

COMPARE SOA SYSTEM WITH ORGANIZATION

\begin{tabular}{|c|c|c|}
\hline No. & General Features of Organizations & Corresponding Features of SOA Systems \\
\hline 1 & They all contain people. & They all contain services. \\
\hline 2 & $\begin{array}{l}\text { The people in an organization perform different roles and } \\
\text { their continued membership of the organization is dependent } \\
\text { upon such performance. }\end{array}$ & $\begin{array}{l}\text { The services in an SOA system perform different units of functionality and } \\
\text { their continued adoption in the SOA system depends on such working } \\
\text { performance. }\end{array}$ \\
\hline 3 & $\begin{array}{l}\text { The organization has a collective goal to which all members } \\
\text { subscribe. }\end{array}$ & The SOA system has a particular goal to which all services freely agree. \\
\hline 4 & $\begin{array}{l}\text { All of the roles, taken together, help the organization achieve } \\
\text { its collective goal. }\end{array}$ & $\begin{array}{l}\text { All of the units of functionality, taken together, help the SOA system } \\
\text { achieve its particular goal. }\end{array}$ \\
\hline 5 & $\begin{array}{l}\text { Difference tasks are distributed to different individuals } \\
\text { according to their expertise, interest or specialism. }\end{array}$ & $\begin{array}{l}\text { Different services undertake different work according to their functional } \\
\text { capability and non-functional performance. }\end{array}$ \\
\hline 6 & $\begin{array}{l}\text { There is a clearly defined hierarchy of authority so that each } \\
\text { member of the organization is aware of where he or she 'fits } \\
\text { in'. }\end{array}$ & $\begin{array}{l}\text { Whether a service is aware of its contribution to the SOA system or not } \\
\text { depends on the mechanism of service composition. The services involved } \\
\text { in choreography will understand their positions, timing of operations, and } \\
\text { the interaction with other participants. However, the services involved in } \\
\text { orchestration even need not be aware of their involvement. }\end{array}$ \\
\hline 7 & $\begin{array}{l}\text { The limits or borders of an organization are usually clearly } \\
\text { defined. This means that there is usually no doubt whether a } \\
\text { particular person is 'inside' or 'outside' of the organization. }\end{array}$ & $\begin{array}{l}\text { For the whole SOA system, the limits or borders are indeed clearly } \\
\text { defined. In other words, there is no doubt whether a particular service is } \\
\text { included in or excluded from the SOA system. }\end{array}$ \\
\hline
\end{tabular}




\section{TACKLING SOSE CHALLENGES USING SOLUTIONS WITHIN ORGANIZATION THEORY}

Kontogiannis et al. [14] classify the SOSE challenges into four research topics: Business, Engineering, Operations and Cross-Cutting. Benefiting from switching the research environment of SOSE, we can explore solutions within the organization theory domain to resolve these four types of challenges. As preliminary work, here we only identify four solutions each of which is an example to some challenge under the corresponding research topic.

\section{A. The Business Topic: To Build Business Process Teams to Facilitate Mapping between Business Structure and Service-Oriented Environment}

In organizations, teams are cross-functional structures that bring people outside the scope of traditional departments to work together and share collective responsibility for special and complex assignments. A business process team is established around one business process and includes people who can collectively perform all the major activities to carry out the business process from beginning to end. Business process teams exist as a characteristic of "horizontal organizations" [8]. Horizontal organizations instinctively tend to flatten their structures by focusing on all the units involved in completing a certain work, rather than the coordinate activities relying on a vertical hierarchy. As a result, horizontally established business process teams have advantages of reduced management costs and less need for coordination. An organization can build different teams for different business processes. Meanwhile, team members can still remain their conventional department positions, and simultaneously join different business process teams according to their knowledge and skills.

Building business process teams in an SOA system should be a virtual division instead of a real action. In other words, all the services involved in a business process logically constitute a team without changing existing structure of the SOA system. Through virtual business process teams, the focus of coordination and control can be balanced between inward IT and outward business during SOA implementations. Furthermore, considering one service can be involved in different business process teams like the same scenario of organizational teams, we can identify and scale services' dependency of business processes in an SOA system. The more dependency a service has, the more carefully it should be controlled especially when planning to change or adapt this service. Incidentally, the philosophy behind business process team is that all the team members must understand the whole working process, and how they should contribute and cooperate with each other to satisfy the final target. Therefore, virtually building business process teams is particularly suitable for the mechanism choreography among involved services when implementing SOA.

\section{B. The Engineering Topic: To use TQM to Accommodate to the Quality Assurance Challenges}

After the first introduction by Dr. Deming in the late 1950s, TQM was conceptualized as an appropriate resource to promote organizational innovation. Innovation has been widely recognized as a competitive instrument essential for organizations' long-term success and survival. In other words, organizations can use innovation to adapt and fit the changing conditions of environment like technology and market [10]. Therefore, TQM can be employed as a strategic choice to instruct organizations to be aligned with their environment. Just as the name implies, TQM is a holistic level management for quality, because it can be achieved only if the total quality concept is utilized from the acquisition of resources to the customer satisfaction [11].

In the discipline of SOA, the quality management has also been emphasized to satisfy the unique characteristics of service-oriented computing. Nevertheless, to the best of our knowledge, existing research into quality management in SOA area mainly hover at the service level, which is limited around the Quality of Service (QoS). The overall QoS of an SOA system is determined by all the QoS of component services who compose the SOA system [12]. Based on the QoS management, SOA systems generally replace component services with higher quality services to realize adaptations. Hence, the focus of QoS management is on individual services in SOA environment.

When applying TQM to SOA domain, the interaction and cooperation process among services will be focused. Quality of processes is emphasized in the implementation framework of TQM constructed by Deming's 14 points [13]. In any circumstance, processes should be constantly analyzed to determine what changes can be made to bring improvement. Therefore, TQM introduces a new angle of view to SOA systems when adapting environment. However, employing TQM does not indicate abandoning QoS management. There is no conflict between TQM and QoS management. On the contrary, they are two complementary approaches for SOA to accommodate the changing environment: (1) TQM can be used to adjust the process of interaction and cooperation among services. (2) QoS management can be used to switch services based on the latest quality requirement.

\section{The Operations Topic: To Flatten the Structure to Meet the Challenge of the Adoption of Composite Services}

In an organizational hierarchy, the number of levels typically increases along with that the organization grows and becomes more complex. However, every level in a hierarchy will inevitably add considerably operating costs [16]. Moreover, an organization having too tall hierarchy may come with long decision making chain and slow responsiveness to customers. Therefore, organizations can increase efficiency by keeping their structures as flat as possible. Furthermore, flat structure can decentralize responsibility and control to lower-level employees to take greater advantage of the skills and experience of organizational members. 
In an SOA system's hierarchy, the number of levels can increase along with the growing cascade of service composition. If some business logic involves several business pieces that reside in different services, it can be realized by composing these services and exposed as a new composite service. In general, composite service is recursively defined as an aggregation of elementary and composite services. When thinking of SOA from organizational perspective, composite services play integrative roles in an SOA system. In organizations, an integrative role is a full-time manager who is in charge of orchestrating work across units [9]. These managers have accountability for results but are not directly responsible for the resource achieving and specific work that should be accomplished by member staff. If the organizational structure is flattened, the number of integrative roles will be reduced.

\section{The Cross-Cutting Topic: To Take Measurements at Interim Steps in Process to Satisfy the Governance Challenge}

When generating products following certain working processes or designing the working processes themselves in an organization, the processes are always governed by measuring outcomes. On the other hand, it is also valuable to take measurements at interim steps in processes. The research and practice in organizations during last few decades reveal that it is increasingly important to ensure the work finished properly the first time instead of having to be redone [8]. Consequently, the inspections and measurements can be applied to different steps in processes to save the cost of rework and avoid flaws in the end product.

When applying this solution to SOA implementation, the inspiration is to confirm the individual work of each service in processes. The essential behind this solution is to define clearly connected subtasks in a process, and specify and measure the result of each subtask. It should be noted that measuring interim task mainly concerns the result rather than how the task is performed. Considering a service is such an entity that performs some task while hides technical details, we can use the interim task measurement to help identify the most suitable services. Once all the services are determined, the relevant business process can then be correctly implemented.

\section{CONCLUSION}

There are still a number of challenges covering a wide scope of SOSE area. Since both application and research in the SOSE area could be negatively influenced before reducing those challenges, it is necessary to find efficient approaches to relieve the research effort and resolve existing challenges. To satisfy aforementioned requirement, this paper justifies that we can introduce the fruitful work in organizational theory domain to current SOSE challenges. By viewing SOA from an organization perspective, we have identified four solutions each of which can resolve one challenge under one of the predetermined research topics. Through the four identified solutions, we can find that existing work within organization theory domain is possible to facilitate resolving challenges under every research topic of SOSE area. Therefore, our future work is to explore other solutions under the umbrella of organization theory to help resolve more SOSE challenges, as well as to motivate more research opportunities in this interdisciplinary area.

\section{REFERENCES}

[1] J. McAuley, J. Duberley, and P. Johnson, Organization Theory: Challenges and Perspectives, 1st ed.. England: Prentice Hall, 2007.

[2] Service-Oriented Architecture Reference Model Technical Committee, Organization for the Advancement of Structured Information Standards, “A Reference Model for Service-Oriented Architecture”, White Paper. Billerica, MA, 2006.

[3] M. Rosen, B. Lublinsky, K. T. Smith, and M. J. Balcer, Applied SOA: Service-Oriented Architecture and Design Strategies. Indianapolis, Indiana: Wiley, 2008.

[4] M. P. Papazoglou and W. -J. Heuvel, "Service Oriented Architectures: Approaches, Technologies and Research Issues,” The VLDB Journal, Vol. 16, No. 3, July 2007, pp. 389-415.

[5] J. Bakan, The Corporation: The Pathological Pursuit of Profit and Power. New York: Free Press, 2005.

[6] D. Campbell and T. Craig, Organisations and the Business Environment, 2nd ed.. Burlington, MA: Butter-worth-Heinemann, 2005.

[7] Q. Gu and P. Lago, "Exploring Service-Oriented System Engineering Challenges: a Systematic Literature Review," Service Oriented Computing and Applications, Vol. 3, No. 3, July 2009, pp. 171-188.

[8] M. R. Davis and D. A. Weckler, A Practical Guide to Organization Design. Menlo Park, California: Crisp Publications, Inc., 1996.

[9] A. Kates and J. R. Galbraith, Designing Your Organization: Using the STAR Model to Solve 5 Critical Design Challenges. San Francisco, CA: Jossey-Bass, November 2007.

[10] M. L. Santos-Vijande and L. I. Alvarez-Gonzalez, "Innovativeness and Organizational Innovation in Total Quality Oriented Firms: The Moderating Role of Market Turbulence,” Technovation, Vol. 27, No. 9, September 2007, pp. 514-532.

[11] H. Kaynak, “The Relationship between Total Quality Management Practices and their Effects on Firm Performance," Journal of Operations Management, Vol. 21, No. 4, July 2003, pp. 405-435.

[12] S. S. Yau, N. Ye, H. Sarjoughian, and D. Huang, "Developing Service-based Software Systems with QoS Monitoring and Adaptation,” Proc. 12th IEEE International Workshop on Future Trends of Distributed Computing Systems (FTDCS 2008), IEEE Computer Society, December 2008, pp. 74-80.

[13] M. Walton, The Deming Management Method. New York, NY: Perigee Books, November 1988.

[14] K. Kontogiannis, G. A. Lewis, and D. B. Smith, “A Research Agenda for Service-Oriented Architecture,” Proc. 2nd International Workshop on Systems Development in SOA Environments (SDSOA’08), ACM, May 2008, pp. 1-6.

[15] M. P. Papazoglou, P. Traverso, S. Dustdar, and F. Leymann, "Service-Oriented Computing: State of the Art and Research Challenges,” Computer, Vol. 40, No. 11, November 2007, pp. 38-45.

[16] J. George and G. Jones, Understanding and Managing Organizational Behavior, 5th ed.. Boston, MA: Prentice Hall, March 2007.

[17] H. Demirkan, R. J. Kauffman, J. A. Vayghan, H.-G. Fill, D. Karagiannis, and P. P. Maglio, "Service-Oriented Technology and Management: Perspectives on Research and Practice for the Coming Decade,” Electronic Commerce Research and Applications, Vol. 7, No. 4, Winter 2008, pp. 356-376.

[18] K. Kontogiannis, G. A. Lewis, D. B. Smith, M. Litoiu, H. Muller, S. Schuster, and E. Stroulia, "The Landscape of Service-Oriented Systems: A Research Perspective,” Proc. International Workshop on Systems Development in SOA Environments (SDSOA'07), IEEE Computer Society, May 2007. 